\title{
ACTIVE LAYER THICKNESS RETRIEVAL OVER THE QINGHAI-TIBET PLATEAU FROM 2000 TO 2020 BASED ON INSAR-MEASURED SUBSIDENCE AND MULTI- LAYER SOIL MOISTURE
}

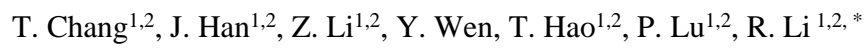 \\ ${ }^{1}$ Center for Spatial Information Science and Sustainable Development, Tongji University, 1239 Siping Road, Shanghai, China - \\ (ctzry, 1832012, 1832018, tonghao, luping, rli) @ tongji.edu.cn, yuliangwen214@gmail.com \\ ${ }^{2}$ College of Surveying and Geo-Informatics, Tongji University, 1239 Siping Road, Shanghai, China
}

Commission III, WG III/9

KEY WORDS: QTP, Permafrost, Active Layer Thickness, SBAS-InSAR, Surface Deformation, Soil Moisture

\begin{abstract}
Active layer thickness (ALT) is an important index to reflect the stability of permafrost. The retrieval of ALT based on Interferometric Synthetic Aperture Radar (InSAR) technology has been investigated recently in permafrost research. However, most of such studies are carried out in a limited extend and relatively short temporal coverage. The combination of temporal-spatial multi-layer soil moisture data and multi-temporal InSAR is a promising approach for the large-scale characterization of ALT. In this study, we employed Small Baseline Subset Interferometry (SBAS-InSAR) technology to obtain the seasonal surface deformation from radar images of Envisat and Sentinel-1 in a permafrost region of Qinghai-Tibet Plateau (QTP). We attempt to verify and calibrate the temporal-spatial multilayer soil moisture product in combination with the in-situ data. Based on the land subsidence data and the temporal-spatial multi-layer soil moisture data, we further improve method to retrieve the ALT information. This paper describes the progress so far and point out the future work.
\end{abstract}

\section{INTRODUCTION}

Permafrost, as an important component of the cryosphere, is particularly sensitive to climate change (Wu et al., 2002; Li et al., 2008; Gruber et al., 2012). Qinghai-Tibet Plateau (QTP) is the highest altitude and largest permafrost distribution area in the middle and low latitudes of the world (Lu et al., 2017; Xu et al., 2017). In the context of global warming, temperature in QTP increased at a rate of $0.6^{\circ} \mathrm{C} / 10 \mathrm{a}$ over the period of 1980 2007 (Wu et al., 2013). Permafrost on QTP has unique hydrothermal properties and is unstable (Wang et al., 2017). The complex geographical environment of QTP makes the permafrost more sensitive to global warming. The permafrost is facing degradation problems. The active layer thickness (ALT) is an important index to reflect the stability of permafrost (Luo et al., 2014). The existing research results show that the ALT in the hinterland of QTP increases at an average rate of 3.6-7.5 cm/a (Wu et al., 2010; $\mathrm{Li}$ et al., 2012; $\mathrm{Li}$ et al., 2019). Changing of ALT may affect local environmental conditions and engineering infrastructure (Jin et al., 2000; Zhang et al., 2005; Pang et al., 2009). Due to the harsh environment of QTP, it is not suitable for large-scale field measurement, so it is more practical to monitor with longterm and large-area satellite remote sensing data, which gradually become an important information source for largescale frozen soil mapping (Zou et al., 2017; Ran et al., 2021). Many researchers have proposed various models to estimate ALT, such as empirical statistical model, hydrothermal coupling numerical model, and inversion model based on InSAR deformation data (Wang et al., 2009).

Remote sensing techniques, such as Interferometric Synthetic Aperture Radar (InSAR), can provide permafrost induced surface deformation measurements that can be used for ALT estimation over large areas with fine spatial resolution (Liu et al., 2009, 2012; Zhang et al., 2020). With the development of D-InSAR technology and time-series InSAR technology, more and more researchers try to use InSAR technology to monitor the changes of surface deformation and ALT in permafrost regions. Freeze-thaw process of frozen soil is a complex process, which is affected by many factors (Dan and Jian-Kun, 2013), and it is difficult to directly retrieve the ALT from surface deformation. At present, ALT retrieval based on InSAR technology is still in the exploratory stage. Liu et al. (2012) proposed a model of ALT obtained through surface deformation derived from the phase transition relationship between ice and water in the active layer, and successfully used Small Baseline Subset Interferometry (SBAS-InSAR) technology to simulate the ALT in northern Alaska. Li et al. (2015) estimated the ALT in combination with time-series deformation of the Yangbajing-Dangxiong region by deriving the one-dimensional heat conduction formula. Wang et al. (2018) proposed an ALT retrieval model based on ground subsidence, land cover types, and groundwater information. Zhang et al. (2020) introduced SMAP L4 surface and root zone soil moisture data and ERA-Interim reanalysis soil moisture data to calculate the ALT in Wudaoliang area by using piecewise multi-layer ALT retrieval model based on InSAR technology. However, most of the existing methods are carried out in a limited extend and relatively short temporal coverage. Previous studies have shown that the seasonal surface deformation of permafrost and soil moisture at different depths can be used to estimate ALT throughout the entire melting season. The combination of temporal-spatial multilayer soil moisture data and the multi-temporal InSAR technology is a promising approach for the large-scale characterization of ALT (Zhang et al., 2020).

Corresponding author 
In this study, we report our progress on the efforts to employ SBAS-InSAR technology to retrieve the seasonal surface deformation with the radar images of Envisat and Sentinel-1 and to verify and calibrate the multi-layer soil moisture product in combination with the in-situ data. Based on the land subsidence data and multi-layer soil moisture data, we further improve the ALT retrieval model. The challenge remains in the calibration of large-scale multi-layer soil moisture products due to a lack of in-situ datasets in permafrost regions of QTP.

\section{DATA}

\subsection{Permafrost Type Distribution Map}

The permafrost type distribution map with a spatial resolution of $1 \mathrm{~km}$ used in this study is the result of Zou et al. (2017) which is derived using the table temperature of permafrost (TTOP) model.

\subsection{SAR Images}

The Envisat satellite, one of the European Aviation Agency (ESA) Earth observation satellites, was launched on 1 March 2002. The satellite carries advanced synthetic aperture radar (ASAR), which works in a $\mathrm{C}$ band with a wavelength of 5.6 $\mathrm{cm}$ in a dual-polarization mode and provides Earth observation data with a period of 35 days, and can generate high-quality and high-resolution images of ocean, coast, polar ice cap and land (Pottier and Ferro-Famil, 2008). In QTP, the ascending orbit data and descending orbit data basically covered 20062011 and 2003-2011 respectively.

The Sentinel-1 satellite, launched on 3 April 2014, is an earth observation satellite in the global monitoring for environment and security program (GMES) of ESA. It consists of two satellites and carries C-band synthetic aperture radar, which can provide an all-weather, day-and-night supply of imagery of Earth's surface (Geudtner and Torres, 2012). It has the ability of dual polarization, short revisit period and rapid production (Dan and Jian-Kun, 2013). The SAR instrument supports four imaging modes providing different resolutions and coverage (Yague-Martinez et al., 2016). Its interferometric wide swath (IW) mode is realized by a new technology called the Terrain Observation by Progressive Scans (TOPSAR) operation. This technique has the advantages of high geometric resolution and enhanced signalto-noise ratio (Farkas et al., 2015; Lu et al., 2020a).

The surface deformation of QTP was retrieved by applying the SBAS-InSAR method with SAR images of Envisat from 2003 to 2010 and Sentinel-1 from 2014 to 2019 . The Envisat and Sentinel-1 SAR images were processed for the periods, respectively. The level 1 single look complex (SLC) images of Envisat with VV polarization were selected to monitor surface deformation. As for Sentinal-1, the interferometric wide-swath (IWS) mode is adopted as the main acquisition mode, which has a unique azimuth data acquisition mode of Terrain Observation with Progressive Scans (TOPS) (Wegnüller et al., 2016; Lu et al., 2020b).

\subsection{GPS Data and Borehole Data}

We obtained the GPS and levelling measurement data of the natural surface near the Qinghai-Tibet Railway from 2003 to 2007 provided by the China Railway First Survey and Design
Institute, which is used to verify the obtained surface deformation. GPS data has a temporal resolution of about 15 days, with a total of 12 survey areas. In each measurement area, GPS receivers were placed on the left and right shoulders of the railway and the foot of the left and right slope respectively to obtain the deformation sequence of the railway subgrade and its surrounding areas. Due to the small scale of railway width compared with the resolution of InSAR results, only 24 GPS observation sequences from the left and right slope toes of 12 survey areas were used for verification.

Eighteen of the borehole sites, which were used to validate the simulated ALT results, were adapted from Qin et al. (2017). The borehole sites are distributed in the middle of QTP and the observed ALT from 2010 to 2012 was compared with the corresponding simulated ALT.

\section{METHODS}

\subsection{Seasonal Deformation Model Based On InSAR}

In the permafrost region of QTP, the surface displacement shows obvious seasonal variation (Zhang et al., 2019; Lu et al., 2020a). The objective of this study was to monitor the freezethaw seasonal displacement in the selected permafrost regions of QTP. InSAR methods have advantages in monitoring surface deformation with high temporal and spatial resolution, and at a millimeter precision ( $\mathrm{Li}$ et al., 2019). In particular, multi-temporal InSAR (MT-InSAR) analysis can remove those disturbances induced by inaccurate DEM, atmospheric delays and spatiotemporal decorrelation (Ferretti et al., 2001; Crosetto et al., 2016; Lu et al., 2019).

SBAS-InSAR technique is based on the interference pair of multiple master images, and the time series deformation information is recovered based on high coherence points, which can maintain stable and effective operation in the natural surface conditions such as QTP (Berardino et al., 2002; Chen et al., 2013). The whole process of SBAS-InSAR was completed based on the Swiss interference radar data processing software GAMMA.

The processing consists of four main steps: SAR image coregistration, generating differential interferometric sets, estimating spatially-correlated atmospheric phases and deformation estimation. First, the ESA precision state vectors were adopted to reduce the impact of inaccurate baseline. SAR images in the middle of time series were selected as geometric reference images for registration, so as to ensure a large common coverage range and high coherence coefficient. After the co-registration, the $30 \mathrm{~m}$ Shuttle Radar Topographic Mission (SRTM) was used to remove the topographic phase and unwrap differential interferograms. In the process of generating differential interferogram, the residual linear phase trend caused by spatial baseline error is eliminated. The singular value decomposition (SVD) method is used to transform the multi-reference set into a single reference time series. The residual atmospheric phases were removed by using the last regression. The final step was to convert the phase signals to cumulative surface deformations along the line of sight. A detailed description of the SBAS-InSAR processing can be found in our previous study ( $\mathrm{Lu}$ et al., 2020b).

\subsection{ALT Retrieval Model}

When the melt season begins, the active layer melts from the 
top down, and the ice in the soil of the active layer melts into water. Because of the volume difference of ice-water phase transition, the surface subsidence occurs. The model assumes that the surface subsidence is entirely caused by the phase transition of ice and water in the active layer, and can relate the surface subsidence to the ALT. The relationship can be simplified and described as follows (Liu et al., 2012):

$$
\Delta D=\int_{0}^{H} W \frac{\rho_{\text {water }}-\rho_{\text {ice }}}{\rho_{\text {ice }}} d h
$$

where $\Delta D$ is the seasonal deformation (m), $H$ is the ALT (m), $W$ is the soil moisture $\left(\mathrm{m}^{3} / \mathrm{m}^{3}\right), \rho_{\text {water }}$ is the density of water $\left(\mathrm{g} / \mathrm{cm}^{3}\right), \rho_{\text {ice }}$ is the density of ice $\left(\mathrm{g} / \mathrm{cm}^{3}\right)$.

Soil moisture is an important factor and varies during melt season with time and different soil depths. Therefore, multilayer soil moisture data were introduced into the model to establish a piecewise multi-layer ALT retrieval model, as follows (Zhang et al., 2020):

$$
H=\sum_{i}^{K} \Delta H_{i}=\frac{\rho_{\text {ice }}}{\rho_{\text {water }}-\rho_{\text {ice }}} \sum_{i}^{K} \frac{\Delta D_{i}}{\bar{W}_{i, j}}
$$

where $H$ is the $\operatorname{ALT}(\mathrm{m}), K$ is the total number of time intervals, $i(i=1,2, \ldots K)$ is the specific time interval, $\Delta H_{i}$ and $\Delta D_{i}$ is the thawing depth (m) of the permafrost and the seasonal deformation in a specific time interval, respectively. $j$ is the specific soil depth layer, $\bar{W}_{i, j}$ is the mean soil moisture $\left(\mathrm{m}^{3} / \mathrm{m}^{3}\right)$ in a specific soil depth layer during a specific time interval.

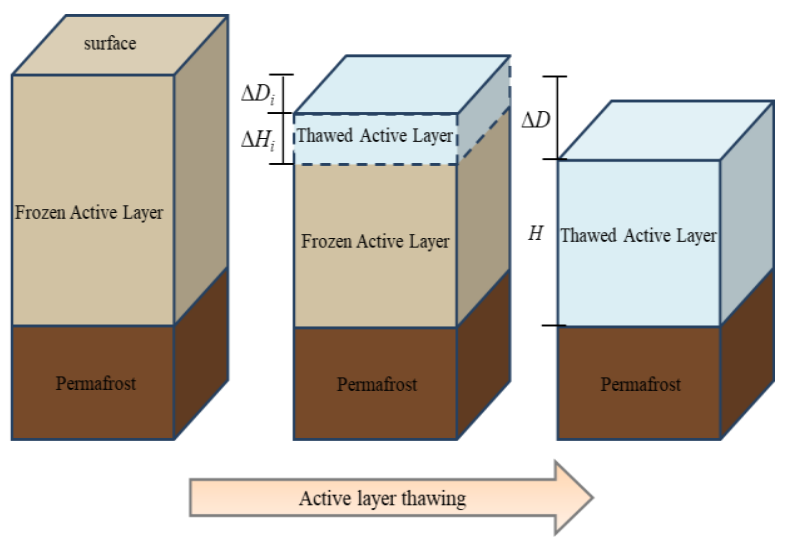

Figure 1. Active layer thawing process (diagrams are not to scale), modified from (Liu et al., 2012)

The changing state of the active layer in the process mainly includes three stages, as illustrated in Figure 1. Before the start of the melt season, the entire active layer is frozen. When the melt season begins, the top of the active layer thaws gradually, the thawing depth of the soil increases and the surface appears a trend of subsidence. At the end of the melt season, the entire active layer melts to its maximum thickness and the surface reaches its maximum subsidence. The piecewise multi-layer ALT retrieval model divides the entire melt season into multiple equal time intervals and divides the soil into specific depth layers. The ALT can be obtained by accumulating the thawing depth of permafrost in each time interval. The selection of the specific soil depth layer is based on the accumulation of the thawing depth, then soil moisture is selected according to a specific soil depth layer.

\section{RESULTS}

\subsection{Surface Deformation}

The surface deformation obtained by MT-InSAR technology can provide reliable data input for the research of ALT. At present, we have processed and obtained the results of surface deformation in the Hoh Xil region of QTP, as illustrated in figure 2 .

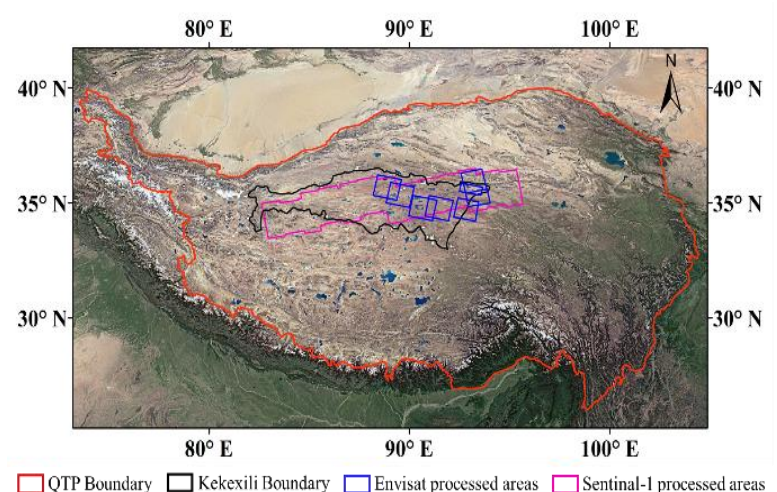

Figure 2. The areas processed by InSAR
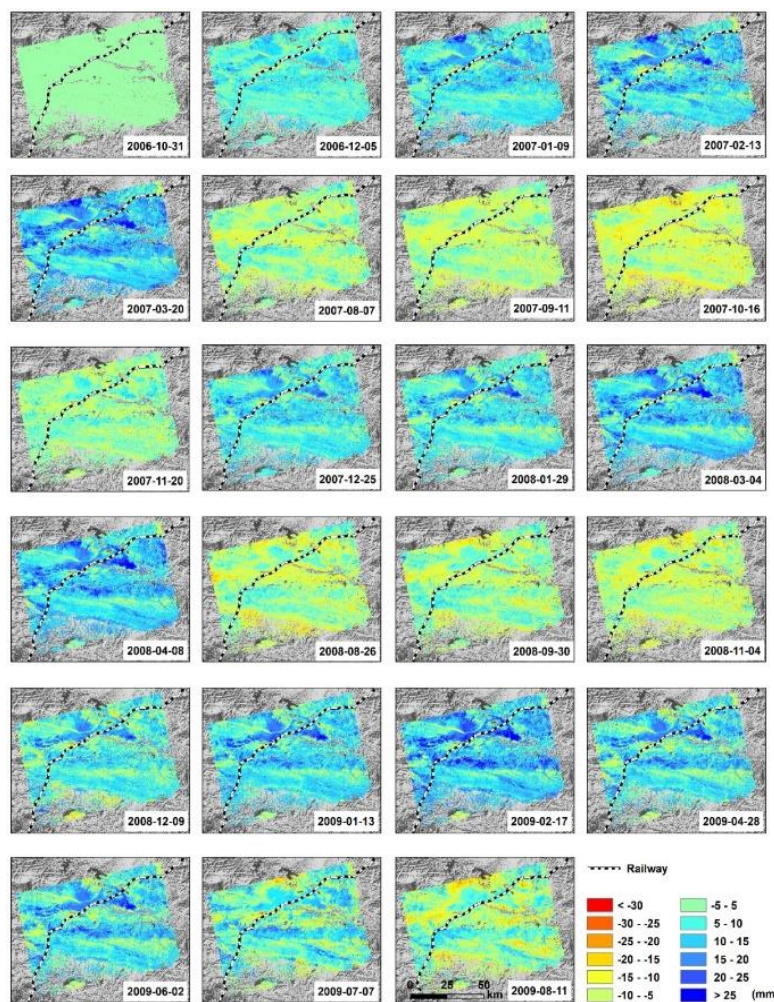

Figure 3. Line-of-sight deformation in Wudaoliang region

We selected Wudaoliang region of QTP to analyze the surface deformation. The results in figure 3 show a pattern of seasonal rise and subsidence. In summer, the active layer melts and the surface subsides; In winter, the active layer freezes and the surface rises. The surface deformation results were verified by 
using the measured data. We used the Kolmogorov-Smirnov test (KS-test) to verify whether the two data sequences had the same trend (Hanusz and Tarasińska, 2015). 22 of the 24 GPS elevation measurement points passed the KS test. In addition, the average error of the 24 sequences was $6.4 \mathrm{~mm}$, which is slightly higher than the empirical error value $(5 \mathrm{~mm})$ of urban surface deformation. Considering the more complex disturbance factors under the natural surface, the results were acceptable.

\subsection{Active Layer Thickness Modeling}

Our initial work used a combination of Stefan model and MODIS LST products to calculate ALT. The simulated results indicate the ALT is larger along the borders between permafrost areas and seasonally frozen ground areas. It is found that the ALT is thin in the permafrost hinterland and thick along the edges of the permafrost regions. The observed ALT values at 18 borehole sites over the period from 2010 to 2012 were used for validation of the estimated ALT in 2011. For the initial estimate of ALT in central region of QTP, the average ALT is $2.2 \mathrm{~m}$ with a standard deviation of $0.32 \mathrm{~m}$. The estimated error in the ALT from the 18 sites ranges from -0.19 $\mathrm{m}$ to $-1.58 \mathrm{~m}$, so our estimates are generally larger than the borehole data. And these results have relatively larger errors than the GIPL2 model (Qin et al., 2017). We are extending the model in Equations 1 and 2 in terms of both seasonal surface deformation and soil-depth-type information of moisture to optimize the piecewise multi-layer ALT retrieval model in QTP. We plan to complete the experimental area in the middle of QTP in figure 2, and then extend potentially to the entire plateau.

\section{CONCLUSIONS}

We obtained surface deformation time series in Hoh Xil area of QTP by SBAS-InSAR technology from Envisat SAR images from 2003 to 2010 and Sentinel-1 from 2014 to 2019. The effects caused by the terrain and atmospheric factors are reduced or removed in the GAMMA software system. We selected surface points of various terrain types to examine the amplitude, trend and phase of the surface deformation. They are further compared with a set of in-situ deformation measurements and found to be comparable. The validated deformation information showed a clear pattern of seasonal rise and subsidence and can be input into the multi-layer ALT modelling system.

We have been evaluating different soil moisture remote sensing products. By comparing with the in-situ soil moisture data measured in QTP, we select the soil moisture product with high resolution and accuracy. The challenge remains in obtaining knowledge about multi-layer water content with different soil type in the QTP region. Future work will focus on integrated approaches using large scale satellite surface soil moisture data products combined with in-situ measurements of multi-depth water content data.

\section{ACKNOWLEDGEMENTS}

This work has been supported by the National Key Research \& Development Program of China (No. 2017YFA0603100)

\section{REFERENCES}

Berardino, P., Fornaro, G., Lanari, R., Sansosti, E., 2002. A new algorithm for surface deformation monitoring based on small baseline differential SAR interferograms. IEEE Trans. Geosci. Remote Sens. 40, 2375-2383. https://doi.org/10.1109/ TGRS.2002.803792

Chen, F., Lin, H., Zhou, W., Hong, T., Wang, G., 2013. Surface deformation detected by ALOS PALSAR small baseline SAR interferometry over permafrost environment of Beiluhe section, Tibet Plateau, China. Remote Sens. Environ. 138, 10-18. https://doi.org/10.1016/j.rse.2013.07.006

Crosetto, M., Monserrat, O., Cuevas-González, M., Devanthéry, N., Crippa, B., 2016. Persistent Scatterer Interferometry: A review. ISPRS J. Photogramm. Remote Sens. 115, 78-89. https://doi.org/10.1016/j.isprsjprs.2015.10. 011

Dan, C., Jian-Kun, L., 2013. Review of the influence of freezethaw cycles on the physical and mechanical properties of soil. Sci. Cold Arid Reg. 5, 457. https://doi.org/10.3724/SP.J.1226. 2013.00457

Farkas, P., Hevér, R., Grenerczy, G., 2015. Geodetic integration of Sentinel-1A IW data using PSInSAR in Hungary, in: EGU General Assembly Conference Abstracts, EGU General Assembly Conference Abstracts. p. 13483.

Ferretti, A., Prati, C., Rocca, F., 2001. Permanent scatterers in SAR interferometry. IEEE Trans. Geosci. Remote Sens. 39, 8 20. https://doi.org/10.1109/36.898661

Geudtner, D., Torres, R., 2012. Sentinel-1 system overview and performance, in: 2012 IEEE International Geoscience and Remote Sensing Symposium. Presented at the IGARSS 2012 - 2012 IEEE International Geoscience and Remote Sensing Symposium, IEEE, Munich, Germany, pp. 1719-1721. https:// doi.org/10.1109/IGARSS.2012.6351191

Gruber, S., 2012. Derivation and analysis of a high-resolution estimate of global permafrost zonation. The Cryosphere 6, 221-233. https://doi.org/10.5194/tc-6-221-2012

Hanusz, Z., Tarasińska, J., 2015. Normalization of the Kolmogorov-Smirnov and Shapiro-Wilk tests of normality. Biom. Lett. 52, 85-93. https://doi.org/10.1515/bile-2015-0008

Jin, H., Li, H., Wang, S., Zhao, L., 2000. Impacts of Climatic Change on Permafrost and Cold Regions Environments in China. Acta Geogr. Sin. 55, 161. https://doi.o $\mathrm{rg} / 10.11821 / \mathrm{xb} 200002004$

Li, R., Wu, Q., Li, X., Sheng, Y., Hu, G., Cheng, G., Zhao, L., Jin, H., Zou, D., Wu, X., 2019. Characteristic, changes and impacts of permafrost on Qinghai-Tibet Plateau. Chin. Sci. Bull. 64, 2783-2795. https://doi.org/10.1360/TB-2019-0191

Li, R., Zhao, L., Ding, Y., Wu, T., Xiao, Y., Du, E., Liu, G., Qiao, Y., 2012. Temporal and spatial variations of the active layer along the Qinghai-Tibet Highway in a permafrost region. Chin. Sci. Bull. 57, 4609-4616. https://doi.org/10.1007/s1143 4-012-5323-8

Li, X., Cheng, G., Jin, H., Kang, E., Che, T., Jin, R., Wu, L., Nan, Z., Wang, J., Shen, Y., 2008. Cryospheric change in China. Glob. Planet. Change 62, 210-218. https://doi.org/10.1 016/j.gloplacha.2008.02.001 
Li, Z., Cao, Y., Wei, J., Duan, M., Wu, L., Hou, J., Zhu, J., 2019. Time-series InSAR ground deformation monitoring: Atmospheric delay modeling and estimating. Earth-Sci. Rev. 192, 258-284. https://doi.org/10.1016/j.earscirev.2019.03.008

Li, Z., Zhao, R., Hu, J., Wen, L., Feng, G., Zhang, Z., Wang, Q., 2015. InSAR analysis of surface deformation over permafrost to estimate active layer thickness based on onedimensional heat transfer model of soils. Sci. Rep. 5, 15542. https://doi.org/10.1038/srep15542

Liu, L., Schaefer, K., Zhang, T., Wahr, J., 2012. Estimating 1992-2000 average active layer thickness on the Alaskan North Slope from remotely sensed surface subsidence. J. Geophys. Res. Earth Surf. 117. https://doi.org/10.1029/2011JF 002041

Liu, L., Zhang, T., Wahr, J.M., 2009. InSAR measurements of permafrost deformation on the North Slope of Alaska, in: AGU Fall Meeting Abstracts. pp. C51C-0496.

Lu, P., Bai, S., Tofani, V., Nicola Casagli, 2019. Landslides detection through optimized hot spot analysis on persistent scatterers and distributed scatterers. ISPRS J. Photogramm. Remote Sens. 156, 147-159. https://doi.org/10.1016/j.isprsjpr s.2019.08.004

Lu, P., Han, J., Hao, T., Li, R., Qiao, G., 2020a. Seasonal Deformation of Permafrost in Wudaoliang Basin in QinghaiTibet Plateau Revealed by StaMPS-InSAR. Mar. Geod. 43, 248-268. https://doi.org/10.1080/01490419.2019.1698480

Lu, P., Han, J., Li, Z., Xu, R., Li, R., Hao, T., Qiao, G., 2020 b. Lake outburst accelerated permafrost degradation on QinghaiTibet Plateau. Remote Sens. Environ. 249, 112011. https://doi .org/10.1016/j.rse.2020.112011

Lu, Q., Zhao, D., Wu, S., 2017. Simulated responses of permafrost distribution to climate change on the QinghaiTibet Plateau. Sci. Rep. 7, 3845. https://doi.org/10.1038/s4159 8-017-04140-7

Luo, D., HuiJun, J., Marchenko, S., Romanovsky, V., 2014. Distribution and changes of active layer thickness (ALT) and soil temperature (TTOP) in the source area of the Yellow River using the GIPL model. Sci. China Earth Sci. 57, 1834-1845. https://doi.org/10.1007/s11430-014-4852-1

Pang, Q., Cheng, G., Li, S., Zhang, W., 2009. Active layer thickness calculation over the Qinghai-Tibet Plateau. Cold Reg. Sci. Technol. 57, 23-28. https://doi.org/10.1016/j.coldre gions.2009.01.005

Pottier, E., Ferro-Famil, L., 2008. Advances in SAR Polarimetry applications exploiting polarimetric spaceborne sensors, in: 2008 IEEE Radar Conference. Presented at the 2008 IEEE Radar Conference (RADAR), IEEE, Rome, Italy, pp. 1-6. https://doi.org/10.1109/RADAR.2008.4720872

Qin, Y., Wu, T., Zhao, L., Wu, X., Li, R., Xie, C., Pang, Q., Hu, G., Qiao, Y., Zhao, G., Liu, G., Zhu, X., Hao, J., 2017. Numerical Modeling of the Active Layer Thickness and Permafrost Thermal State Across Qinghai-Tibetan Plateau: Numerical Model of Permafrost Dynamics. J. Geophys. Res. Atmospheres 122, 11,604-11,620. https://doi.org/10.1002/201 7JD026858
Wu, Q., Zhu, Y., Liu, Y., 2002. Evaluation model of permafrost thermal stability and thawing sensibility under engineering activity. Cold Reg. Sci. Technol. 34, 19-30. https://doi.org/10.1016/S0165-232X(01)00047-7

Ran, Y., Li, X., Cheng, G., Nan, Z., Che, J., Sheng, Y., Wu, Q., Jin, H., Luo, D., Tang, Z., Wu, X., 2021. Mapping the permafrost stability on the Tibetan Plateau for 2005-2015. Sci. China Earth Sci. 64, 62-79. https://doi.org/10.1007/s11430020-9685-3

Wang, C., Zhang, Z., Zhang, H., Zhang, B., Tang, Y., Wu, Q., 2018. Active Layer Thickness Retrieval of Qinghai-Tibet Permafrost Using the TerraSAR-X InSAR Technique. IEEE J. Sel. Top. Appl. Earth Obs. Remote Sens. 11, 4403-4413. https://doi.org/10.1109/JSTARS.2018.2873219

Wang, C., Jin, S., Wu, Z., Cui, Y., 2009. Evaluation and Application of the Estimation Methods of Frozen (Thawing) Depth over China. Adv. Earth Sci. 24, 132. https://doi.org/10.11867/j.issn.1001-8166.2009.02.0132

Wang, Z., Wang, Q., Wu, X., Zhao, L., Yue, G., Nan, Z., Wang, P., Yi, S., Zou, D., Qin, Y., Wu, T., Shi, J., 2017. Vegetation Changes in the Permafrost Regions of the Qinghai-Tibetan Plateau from 1982-2012: Different Responses Related to Geographical Locations and Vegetation Types in HighAltitude Areas. PLOS ONE 12, e0169732. https://doi.org/10.1 371/journal.pone.0169732

Wegnüller, U., Werner, C., Strozzi, T., Wiesmann, A., Frey, O., Santoro, M., 2016. Sentinel-1 Support in the GAMMA Software. Procedia Comput. Sci. 100, 1305-1312. https://doi. org/10.1016/j.procs.2016.09.246

Wu, Q., Zhang, T., Liu, Y., 2010. Permafrost temperatures and thickness on the Qinghai-Tibet Plateau. Glob. Planet. Change 72, 32-38. https://doi.org/10.1016/j.gloplacha.2010.03.001

Wu, T., Zhao, L., Li, R., Wang, Q., Xie, C., Pang, Q., 2013. Recent ground surface warming and its effects on permafrost on the central Qinghai-Tibet Plateau: RECENT GROUND SURFACE WARMING AND ITS EFFECTS ON PERMAFROST. Int. J. Climatol. 33, 920-930. https://doi.org /10.1002/joc.3479

Xu, X., Zhang, Z., Wu, Q., 2017. Simulation of permafrost changes on the Qinghai-Tibet Plateau, China, over the past three decades. Int. J. Digit. Earth 10, 522-538. https://doi.org/ 10.1080/17538947.2016.1237571

Yague-Martinez, N., Prats-Iraola, P., Rodriguez Gonzalez, F., Brcic, R., Shau, R., Geudtner, D., Eineder, M., Bamler, R., 2016. Interferometric Processing of Sentinel-1 TOPS Data. IEEE Trans. Geosci. Remote Sens. 54, 2220-2234. https://doi .org/10.1109/TGRS.2015.2497902

Zhang, J., Liu, L., Hu, Y., 2020. Global Positioning System interferometric reflectometry (GPS-IR) measurements of ground surface elevation changes in permafrost areas in northern Canada. The Cryosphere 14, 1875-1888. https://doi.o $\mathrm{rg} / 10.5194 / \mathrm{tc}-14-1875-2020$

Zhang, T., 2005. Spatial and temporal variability in active layer thickness over the Russian Arctic drainage basin. J. Geophys. Res. 110, D16101. https://doi.org/10.1029/2004JD0 05642 
Zhang, X., Zhang, H., Wang, C., Tang, Y., Zhang, B., Wu, F., Wang, J., Zhang, Z., 2020. Active Layer Thickness Retrieval Over the Qinghai-Tibet Plateau Using Sentinel-1 Multitemporal InSAR Monitored Permafrost Subsidence and Temporal-Spatial Multilayer Soil Moisture Data. IEEE Access 8, 84336-84351. https://doi.org/10.1109/ACCESS.2020.2988 482

Zhang, X., Zhang, H., Wang, C., Tang, Y., Zhang, B., Wu, F., Wang, J., Zhang, Z., 2019. Time-Series InSAR Monitoring of Permafrost Freeze-Thaw Seasonal Displacement over Qinghai-Tibetan Plateau Using Sentinel-1 Data. Remote Sens. 11, 1000. https://doi.org/10.3390/rs11091000

Zou, D., Zhao, L., Sheng, Y., Chen, J., Hu, G., Wu, T., Wu, J., Xie, C., Wu, X., Pang, Q., Wang, W., Du, E., Li, W., Liu, G., Li, J., Qin, Y., Qiao, Y., Wang, Z., Shi, J., Cheng, G., 2017. A new map of permafrost distribution on the Tibetan Plateau. The Cryosphere 11, 2527-2542. https://doi.org/10.5194/tc-112527-2017 